\title{
Analysis on the Application of BIM Technology in the Design of Building Rebuilding
}

\author{
Ting Wang
}

Xuzhou Technician Institute, Xuzhou, Jiangsu, 221000, China

Keywords: BIM technology; building information model; energy-saving reform; transformation design

\begin{abstract}
In the development of the construction industry in the era of information age, the research on Building Information Modeling (BIM) has been deepening. With the expansion of its application in the industry, it has gradually become a new trend in the industry. Combined with the development status of energy-saving building renovation, this paper analyzes the BIM technology and its research status. With the development of green building and renovation of existing buildings, the renovation of existing buildings based on BIM technology is the development trend of the industry. Based on the study of BIM technology, this paper analyzes the application of BIM technology in building renovation from the planning, design and implementation stages of the reconstruction project, and provides some references for the information transformation and green energy saving of existing buildings.
\end{abstract}

\section{Introduction}

Chuck Eastman, Ph.D. in Architecture and Computing from Georgia Tech College, first proposed the Building Information Model concept, or BIM for short, in a single building model that incorporates all the information for the entire life cycle of a construction project, synthesizing all geometric models Process, information, functional requirements and component performance, construction process, construction schedule, maintenance management, etc. are also included. This concept has been used in the past a variety of formulations such as virtual building, 3D modeling, a single building model.

BIM refers to the design object as a system for research, BIM can simulate the construction project concept process, design process, construction process. With IBM technology, you can give some guidance to practitioners in the construction industry to improve their building technology.

BIM technology and its applications belong to the new academic field, only a few decades of development history. With the rapid development of computer technology in recent years, it has been paid more and more attention in the construction industry. In the process of urbanization and development in our country, large-scale urban construction projects are generally carried out and have a long duration, which provides good conditions for the research and application of BIM technology. In the development of the construction industry, the role of information technology is very important. The use of information technology in the construction industry, BIM technology is a typical representative. The full application of BIM technology can greatly enhance the production efficiency of the construction industry and further enhance the intensification of construction projects, which can significantly improve the quality and efficiency of the entire life cycle of decision-making, design, construction and operation and reduce costs, the development has brought tremendous benefits and revolutionary changes.

With the huge number of existing buildings in our country, with the development of society, these buildings have been unable to meet the current industry standards in terms of energy consumption. For example, the heating, ventilation and air-conditioning systems of some old buildings and the thermal performance of the envelope have not met According to the current industry standards, these existing buildings need to be reformed and need to be analyzed and studied according to the actual situation so as to find the best reformation plan. Therefore, China has conducted in-depth studies on the relevant aspects of building energy-saving technologies and 
energy-saving building concepts and has achieved certain development of. BIM technology is more and more mature, more and more used in the planning, design, construction and post-maintenance phase of the project, providing a new design idea for the reconstruction of existing buildings in China.

\section{BIM Technology Application in the Project Planning Stage}

The existing building renovation is a huge project that is limited in many ways, such as the building's own conditions, the surrounding conditions of the building and the people living inside the building, which are difficult to control. Therefore, the effect of the project modification and the time spent on it are not Well quantified. In the architectural planning stage, the BIM model is established for the building through BIM technology. According to the simulation and simulation technology of BIM technology and its visualization technology, the BIM model is targeted to provide favorable conditions for the project transformation. For example, a factory intends to expand the original building. In the factory, there is a relatively large vacancy between the original staff quarters and the office building. In order to make rational use of this part of the resources, it is planned to expand an office building. However, the larger floor area will affect the environment of the whole campus and affect the comfort of workers. Therefore, BIM can simulate the original model for the project and carry out the simulation of the park comfort to find the most reasonable solution. After BIM model verification, after the office building is completed, the wind speed between the dormitory building and the office building in the park is moderate. The wind speed is mainly in the range of $0.6 \sim 3.9 \mathrm{~m} / \mathrm{s}$ and $1.5 \mathrm{~m}$ above the ground, in line with the industry standards and reasonable utilization Resources, at the project planning stage, provide favorable simulation data verification for the project reconstruction work. Based on the data provided by the BIM model of the building during the project's investment planning and decision-making stages, cost data of the relevant project can be used, such as the cost of basic items and labor in the area where the project is located, cost information for similar projects using this model, BIM model technology, Efficient and accurate planning of the proposed project total investment, which can provide an effective basis for the project investment decisions.

\section{BIM Technology in the Project Design Stage}

In the process of traditional building design, the design of two-dimensional drawings is generally carried out first. After the two-dimensional drawings are completed, the three-dimensional modeling software is used to construct the three-dimensional model. From this we can see that the design process is not only time-consuming It is manpower. The use of IBM technology can directly achieve the construction of three-dimensional model, eliminating the need for intermediate two-dimensional drawings of the design and improve work efficiency.

Building projects can be simulated by BIM technology design, the use of three-dimensional modeling technology in the design process to achieve the sharing of all aspects. In the process of actual building renovation, firstly, the designer constructs the building model according to the requirements of the client, and then passes the building model to the structural designer on the basis of which the further design is carried out. Finally, by the design equipment engineer data collection, entry. Realize the seamless connection of these processes, save time and improve work efficiency.

Compared with the traditional CAD two-dimensional drawing mode, BIM technology uses three-dimensional drawing software to achieve three-dimensional effect, allowing designers to completely get rid of the original two-dimensional drawing mode, the use of BIM technology, designers in the graphic design at the same time, be able to synchronize Generate 3D views, render them as needed, view buildings from different perspectives, and modify architectural designs as needed. The reconstruction of existing buildings, which need to be reformed mainly include the temperature control system of air-conditioning system, energy-saving system of enveloping structure and lighting system. Taking cold and heat source system reformation as an example, it is necessary to rebuild cold and heat source room, but the space for reformation is not big. Compared 
with the new building, the design work is much more complicated, and the equipment and pipeline reformation are heavy workloads. In this complex the case should be used BIM technology, BIM technology will make this situation greatly improved. Using BIM technology, you can view and correct problems in the design process and automatically import 3D data into your analysis software. BIM technology can not only quickly build engineering models, but also project costs and help project cost division engineers complete project budgets and estimates. First of all, the BIM itself is a three-dimensional visualization of the building, which can be consistent with the actual scene in the reconstruction process. Secondly, the BIM reconstruction model includes the geometric attributes of the equipment and the building and other various information so that the visualization model becomes a BIM design the model changes dynamically so that the design model can not only meet the reconstruction requirements, but also provide an important model for the construction reference, to ensure the visual and architectural design consistency dynamic changes.

\section{BIM Technology in the Construction Phase of the Project Application}

Existing building renovation project time, cost control and construction methods are very strict requirements, which is due to the existing building conditions relative to the new building is much more complex, all aspects of the control is more difficult to control factors, there may be the project construction phase is a very important phase of the existing building reconstruction. According to the actual statistics, the contractor often relies on the past project management experience in arranging the construction progress. However, in the actual construction, there is a big difference between the projects, which often leads to the construction progress being obviously lower than the forecast error expected. If the construction progress is not well controlled, the gap between the planned cost and the actual cost will result, and the construction progress will inevitably increase the cost of the construction. The construction phase is the main phase of BIM application and also the key point of BIM research. Firstly, BIM technology is used to simulate the construction of existing buildings, including the simulation of overall construction progress and the simulation of construction technology and construction technology of key nodes. Construction progress, control costs laid a solid foundation. Based on this, we can truly control the efficiency of the construction process, control the construction progress and improve the construction quality; Second, during the construction process, the project can be three-dimensional visual display BIM modeling, construction side if the construction process Encountered problems, through the three-dimensional model, can intuitively quickly understand the design and timely communication with the design side on the construction process, so that problems can be solved in time.

Table 1 Comparison of labor costs

\begin{tabular}{|c|c|c|}
\hline Item category & $\begin{array}{c}\text { According to the original CAD } \\
\text { drawings construction }\end{array}$ & $\begin{array}{c}\text { According to BIM drawings } \\
\text { construction }\end{array}$ \\
\hline Labor costs (yuan / day) & 300 & 300 \\
\hline $\begin{array}{c}\text { Construction period } \\
\text { (days) }\end{array}$ & $5 \sim 10$ & 2 \\
\hline $\begin{array}{c}\text { Construction workers } \\
\text { (people) }\end{array}$ & 3 & 1800 \\
\hline Total price (yuan) & $4500 \sim 9000$ & \\
\hline $\begin{array}{c}\text { Directly save labor costs } \\
\text { (yuan) }\end{array}$ & $2700 \sim 7200$ & 3 \\
\hline
\end{tabular}

Taking a building renovation as an example, during the process of design and renovation, the first to fourth floors have changed their functions. Therefore, the original equipment room pipelines, thermal insulation systems and air-conditioning systems need to be rebuilt. However, the layout of the pipelines is rather complicated. The distance between them is also very close, and the operation and maintenance management are not enough and the operating time is too long, resulting in a very large construction difficulty and a small construction space. In this case, BIM technology was used to simulate the project and build a 3D model map, which facilitated the construction of workers. 
Through the analysis, the use of BIM technology in the project not only saves the economic cost, but also saves the time cost. Analysis of the data shown in Table 1, the labor cost savings for the engine room directly about $3000 \sim 7000$ yuan, the project through the BIM technology in the transformation process of the entire construction progress, the key nodes of the construction process and the integration of mechanical and electrical pipeline simulation, and ultimately Save costs nearly 200,000 yuan.

No matter what kind of construction process, the concept of safety has always been the first one, especially in the construction. Practice has proved that, BIM technology in the construction safety management application, but also achieved very good results. According to the current usage status of BIM technology and the actual characteristics of construction project safety management, a construction safety management model that meets construction safety requirements is constructed based on BIM technology through data collection and analysis. The data layer, the model layer and the application layer are the three main layers of the model. The data comes from the 3D model created by the BIM model and 3DMax software. The model layer is based on the BIM comprehensive information database platform and is produced according to the actual construction. The application layer can the Navidworks 4D construction simulation and collision detection function is applied to the construction stage of site planning, safety analysis, collision detection and program optimization to achieve the purpose of controlling safety risks during the construction of the construction project so as to effectively avoid manual on-site inspection.

\section{BIM Technology Use Process}

Through the above analysis, it has been clear BIM technology in the existing building renovation application. Through the above analysis, BIM technology has the advantages of simulation, visualization, etc. Therefore, the use of BIM technology in construction projects not only can finish the design of the building, but also has great advantages in terms of cost saving and shortening of the construction period and can effectively coordinate the relationship between the various construction units, control the progress of construction, improve the quality and speed of construction. Figure 1 shows the BIM technology in the entire building renovation process.

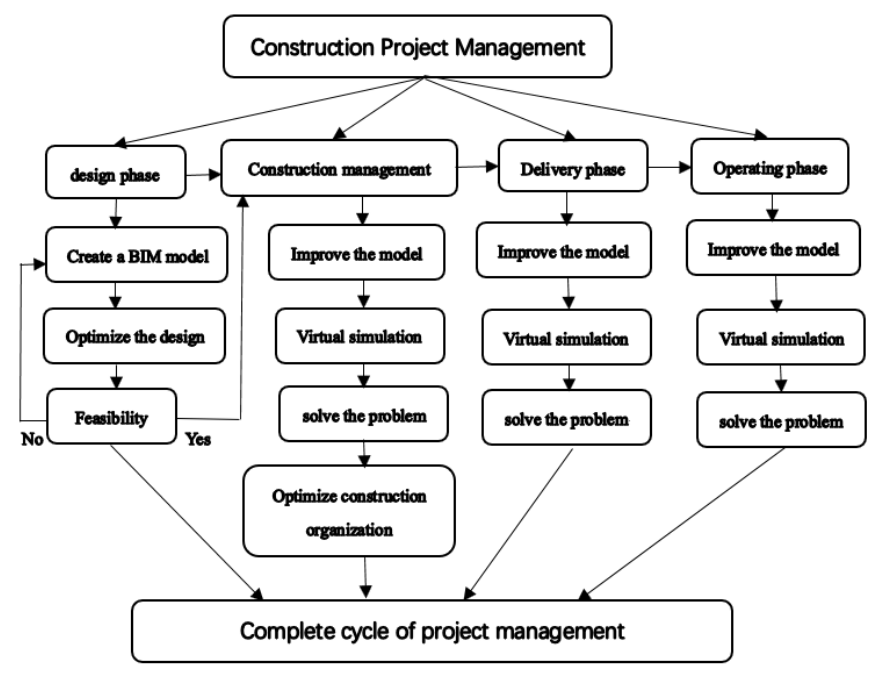

Figure 1 BIM technology in the construction project life cycle application process

\section{Conclusions}

Through the analysis of this paper, BIM technology enables architects to design a virtual model that contains all the information about a building and can import it into relevant software for analysis at any time, and then analyze the obtained analysis results to adjust the plan and improve the building performance, to ensure the scientific construction. Through the analysis of the application of BIM technology to the existing building renovation, it provides guidance for the 
reconstruction of existing building in BIM technology. Compared with the traditional renovation of existing buildings, the existing building renovation based on BIM technology has more advantages in terms of resource conservation and cost control and can achieve the optimal effect of existing building reconstruction.

\section{References}

[1] Building Energy Conservation Research Center of Tsinghua University. China Building Energy Efficiency Annual Research Report [M]. Beijing: China Building Industry Press, 2014.

[2] Zhang Shunyu. BIM technology in the structural design of the transformation of the application [J]. Engineering Construction and Design, 2014, (9): 29-33.

[3] Zhang Wenku. Existing buildings and energy-saving transformation of a variety of building energy-saving technologies and practice [J]. Wall Material Innovation and Building Energy Conservation, 2007 (9): 39-42.

[4] Liu Tong. Application of BIM technology in construction management [J]. Industry, 2016 (11). 